\title{
A FORMAÇÃO INICIAL DE PROFESSORES DE EDUCAÇÃO FÍSICA ALINHADA ÀS PERSPECTIVAS HISTÓRICAS: DO ESTÁGIO À PRÁTICA PEDAGÓGICA
}

\author{
LA FORMACIÓN INICIAL DE PROFESORES DE EDUCACIÓN FÍSICA ALINEADA \\ A LAS PERSPECTIVAS HISTÓRICAS: DE LAS PRÁCTICAS ACADÉMICAS A LA \\ PRÁCTICA PEDAGÓGICA
}

THE INITIAL TEACHERS' EDUCATION IN PHYSICAL EDUCATION LINKED TO HISTORICAL PERSPECTIVES: FROM INTERNSHIP TO PEDAGOGICAL PRACTICE

\author{
Jardielly Alencar VASCONCELOS ${ }^{1}$ \\ Neemias Elnatan SERAFIM ${ }^{2}$ \\ Elialdo Rodrigues de OLIVEIRA ${ }^{3}$
}

RESUMO: O presente artigo busca refletir sobre alguns determinantes no processo histórico da formação inicial dos professores de Educação Física, com o intuito de desvelar os desafios que permeiam a tríade: formação, estágio e prática pedagógica. Por meio do aporte teóricobibliográfico, estabeleceu-se um debate acerca da formação histórica dos professores, perpassando pela especificidade da Educação Física, seguida de uma descrição das implicações presentes nos caminhos percorridos pelos sujeitos em formação. Abordou-se desde os bancos da faculdade até sua prática reflexiva dentro do ambiente escolar. Pelos aportes teóricos evidenciados, depreende-se que é possível ao docente ainda em início de sua carreira, ressignificar sua ação pedagógica de maneira que o viés racional e técnico da sua formação, não sejam os únicos caminhos de verdade absoluta. Por conseguinte, as etapas de estágio contribuam para essa construção cheia de intencionalidades reflexivas.

PALAVRAS-CHAVE: História da formação. Professores de educação física. Estágio. Prática pedagógica.

RESUMEN: El presente artículo busca reflexionar sobre algunos determinantes en el proceso histórico de la formación inicial de los profesores de Educación Física, con el interés en develar los desafios que comprenden la tríada: formación, prácticas académicas y práctica pedagógica. Por medio de aporte teórico-bibliográfico, se estableció un debate acerca de la formación histórica de los profesores. pasando por la especificidad de la Educación Física, seguida de una descripción de las implicaciones presentes en los caminos recorridos por los sujetos en formación. Se abordó desde los asientos de la facultad hasta su práctica reflexiva dentro del medio escolar. Por los aportes teóricos evidenciados se desprende que es posible al docente aún en inicio de carrera, replantear su acción pedagógica de manera que el sesgo racional y técnico de su formación, no sean los únicos caminos de verdad absoluta. Por consiguiente, las

\footnotetext{
${ }^{1}$ Universidade Estadual de Roraima (UERR), Boa Vista - RR - Brasil. Mestranda em Educação. ORCID: <http://orcid.org/0000-0001-6615-1870>.Jardi_ef@hotmail.com

2 Universidade Estadual de Roraima (UERR), Boa Vista - RR - Brasil. Mestrando em Educação. Neemias.serafim@ufrr.br

${ }^{3}$ Universidade Estadual de Roraima (UERR), Boa Vista - RR - Brasil. Doutor em Educação. ORCID: <https://orcid.org/0000-0001-8903-0625>.Elialdo_oliveira@hotmail.com
} 
estapas de las prácticas académicas contribuyan para esa construcción llena de intencionalidades reflexivas.

PALABRAS CLAVE: História de la formación. Profesores de educación física. Prácticas académicas. Práctica pedagógica.

ABSTRACT: This paper work tries to reflect on some determinants in the historical process of initial teachers' education in physical education, in order to exhibit the challenges that permeate the triad: education, internship and pedagogical practice. Through the theoreticalbibliographical contribution, it was settled down a debate about the historical teachers' education, passing through the Physical Education's specificity, followed by a description of the implications present in the paths covered by the person who is in education process. The time in college up to their reflective practice within the school environment has been approached. From the theoretical contributions evidenced, it is possible that the teacher, at the beginning of his career, can re-signify his pedagogical action so that the rational and technical bias of his education are not the only paths of absolute truth. Therefore, the internship stages contribute to this full of reflective intentionalities construct.

KEYWORDS: Education history. Physical education teachers. Internship. Pedagogical practice.

\section{Introdução}

Ao longo da constituição histórica da Educação Física, pode-se perceber que a sua visão em um plano educacional, foi garantia dada pela LDB-9394/1996, enquanto componente curricular obrigatório. Porém, introduzi-la como componente curricular no ambiente escolar, não foi um processo simples. Haja vista que a Educação Física é uma área do conhecimento que sempre evidenciou perspectivas relacionadas às concepções de corpo e movimento (BRASIL, 1997).

Em face desse contexto, pensar na prática do movimento, das atividades físicas dentro do espaço escolar, era algo inconcebível pela sociedade dominante no início do século XX (CASTELANNI FILHO, 2013), pois compreendia-se que elas não poderiam estar no mesmo nível das atividades intelectuais.

Superar o viés da racionalidade técnica e instrumental, estritamente ligada a procedimentos de saber fazer, para assumir nuances que contemplasse outras dimensões do conhecimento como partícipes do processo de formação integral do indivíduo, contribuiu severamente para a deflagração da crise de identidade sofrida na década de 80.

É devido a tais transformações, e ao cenário oriundo destas, que o objetivo central deste artigo é entender os giros epistemológicos sofridos pela Educação Física desde o seu 
surgimento no Brasil, tangente à formação inicial desses professores, bem como demonstrar como se dá a relação tríade de formação, estágio e prática pedagógica, nos dias atuais.

Nessa direção, inicialmente este trabalho apresenta uma breve contextualização sobre formação de professores de maneira abrangente e geral com alguns apontamentos pertinentes. A seguir, trata acerca da área específica da Educação Física, com desdobramentos sobre os processos históricos da formação docente, bem como da saída dos bancos da faculdade para o estágio, e finalmente a prática pedagógica enquanto professor já graduado.

\section{Formação de professores: panorama geral}

A necessidade da formação docente e a preocupação com esse aspecto não são dilemas exclusivos dos tempos atuais. No início do século XIX, países como França, Alemanha, Itália, Inglaterra e Estados Unidos, foram os pioneiros no processo de organização e sistematização da formação de professores, por meio da implementação das Escolas Normais, cujo principal objetivo era o de formar professores para atuar nos níveis primário e secundário.

Dois modelos contrapostos emergem no decorrer desse processo, Saviani (2011). Se por um lado está o modelo dos conteúdos culturais-cognitivos de formação de professores, para o qual a formação tem sua finalidade na cultura geral e no domínio próprio dos conteúdos da área de conhecimento relacionados à disciplina que o professor irá ministrar. Por outro, está o modelo pedagógico-didático de formação de professores, onde a formação só se completa com o exímio preparo pedagógico-didático. Ou seja, além dos conteúdos e especificidades das disciplinas, as instituições formadoras iriam se preocupar com o 'como' e 'de que maneira' os professores iriam lecionar as aulas, pois só assim elas estariam formando professores.

No Brasil, a primeira escola com responsável pela formação de professores foi criada na Província do Rio de Janeiro, pela Lei $\mathrm{n}^{\circ} 10$ de 1835. Segundo Tanuri (2000), esta lei determinava que na capital da Província se situaria uma escola normal para habilitar as pessoas destinadas ao magistério da instrução primária, bem como aqueles professores leigos que não tiverem adquirido necessária instrução nas escolas de ensino mútuo, na conformidade da Lei de $15 / 10 / 1827$.

Nos dois últimos séculos, Saviani (2009) destaca seis relevantes períodos na história da formação de professores no Brasil. Nesta análise, se levou em consideração a pedagogia vigente que se articularam com as mudanças sofridas pela sociedade brasileira ao longo deste tempo. Esses períodos estão assim relacionados: 
1 - Ensaios intermitentes de formação de professores (1827-1890). Esse período se inicia com o dispositivo da Lei das Escolas de Primeiras Letras, que obrigava os professores a se instruir no método do ensino mútuo, às próprias expensas; estende-se até 1890, quando prevalece o modelo das Escolas Normais.

2 - Estabelecimento e expansão do padrão das Escolas Normais (18901932), cujo marco inicial é a reforma paulista da Escola Normal tendo como anexo a escola-modelo.

3 - Organização dos Institutos de Educação (1932-1939), cujos marcos são as reformas de Anísio Teixeira no Distrito Federal, em 1932, e de Fernando de Azevedo em São Paulo, em 1933.

4 - Organização e implantação dos Cursos de Pedagogia e de Licenciatura e consolidação do modelo das Escolas Normais (1939-1971).

5 - Substituição da Escola Normal pela Habilitação Específica de Magistério (1971-1996).

6 - Advento dos Institutos Superiores de Educação, Escolas Normais Superiores e o novo perfil do Curso de Pedagogia (1996-2006) (SAVIANI, 2009. p. 144 - grifos nossos)

O histórico da formação de professores, em âmbito internacional e nacional, revela que a educação é um dos processos mais importantes de uma sociedade. Sendo ato relevante, a formação dos educadores deve disponibilizar às pessoas responsáveis por mediar tal ação, meios para que, de forma autônoma, ofereçam aos seus alunos uma educação pautada não só em conteúdos pré-programados, mas que possibilite novas descobertas e gere um cidadão crítico e responsável. De acordo com Freire (1974), ensinar é uma realização social, um fato cultural, pois é solidificado na relação entre professores e alunos, demonstrando assim a cultura e as conjecturas sociais a que se inserem.

Muitos veem como algo bastante simples a relação entre as palavras ensino e aprendizagem nesse processo denominado Educação. Em uma visão essencialmente tradicional, é o simples fato de alguém (detentor do conhecimento) repassar aquilo que aprendeu a alguém (receptor do conhecimento) de maneira que o detentor seja entendido pelo receptor. Em outras palavras, acredita-se que o professor ensina e o aluno aprende.

Esta interpretação retrógrada se apresenta enfraquecida, pelo menos no âmbito textual, pois ainda é bastante comum encontrar professores que acreditam e praticam esse modo de fazer educação e ensinar. Entretanto, se faz necessário atravessar a teoria e chegar a prática, pois é notório que o significado destes dois termos (ensino e aprendizagem), que não podem ser compreendidos separadamente, expressa a amplitude e o sentido da teoria e da prática pedagógica no processo de aprendizagem, como afirma Lima (2007) o ensino e a aprendizagem trazem subsistência a humanidade.

É notório que a formação do professor é um dos pontos principais para o bom desempenho da máquina da educação e, consequentemente, da sociedade. De acordo com o que 
relata Nóvoa (1992) é preciso reformulações na formação dos professores, nas ações pedagógicas destes docentes e também nas instituições e órgãos educacionais responsáveis, para que a mudança educacional seja efetiva. Vale destacar que o grande entrave é que toda inovação na composição de instituições formadoras de professores e seus cursos esbarram nesse perfil tradicional e nos interesses instituídos (GATTI, 2010), o que acaba dificultando repensar e estruturar essa formação de modo mais significativo.

O contexto do processo de ensinagem mostra que ser professor não é uma tarefa das mais simples como muitos afirmam, requerendo uma dose aumentada de esforço e dedicação. Requer capacidade de refletir sua prática de forma honesta consigo mesmo e ainda estar sensível a necessidade dos alunos enquanto pessoas humanas assim como de toda a comunidade escolar (OLIVEIRA, 2012). O começo do caminho para se analisar os professores e sua formação é justamente contemplar onde acontece essa formação. A princípio se supõe que o início está nos cursos de licenciatura e das instituições de ensino voltadas para tal finalidade. Ao abordar sobre a formação em licenciaturas Gatti (2010) relata:

Hoje, em função dos graves problemas que enfrentamos no que respeita às aprendizagens escolares em nossa sociedade, a qual se complexifica a cada dia, avoluma-se a preocupação com as licenciaturas, seja quanto às estruturas institucionais que as abrigam, seja quanto aos seus currículos e conteúdos formativos (p. 1359).

A preocupação relatada pela autora relacionada aos cursos de licenciatura se dá pelo fato de que é neles que o professor recebe a "base" técnica, pedagógica e específica de sua área para lidar com o ambiente da educação, seja ele fora ou dentro da escola.

Alinhado a esse entendimento Nóvoa (1992) lembra que o papel da formação é gerar no professor em construção uma concepção crítico-reflexiva, que dê sustentação para se gerar um pensamento autônomo, onde o professor de forma particular e exclusiva tem a capacidade para emitir opinião sobre o ensino e a aprendizagem além de buscar subsídios para despertar em seus alunos a crítica sobre tal assunto. O processo de formação requer do professor aplicação pessoal, uma tarefa livre e criativa visando também os seus objetivos e projetos particulares. É nesse percurso que o professor forma sua identidade pedagógica e profissional.

Nesse universo de educadores, de apontamentos e questionamentos sobre formação, se encontra o professor de Educação Física, o responsável, em tese, por ajudar o aluno a desenvolver conhecimento e olhar analítico sobre seu desenvolvimento corporal, cognitivo e emocional e, ainda, promover uma compreensão sobre os movimentos corporais e culturais em suas diversas maneiras de se apresentar. Na tentativa de compreender como se constituiu e 
constitui a formação específica desses professores é que se adentra nas perspectivas históricas a fim de entender a racionalidade técnica expressa nessa área de conhecimento.

\section{Aspectos históricos da formação inicial do professor de Educação Física}

Historicamente, a Educação Física vem assumindo várias facetas que influenciam direta e indiretamente o currículo desta disciplina. Influência que alcança também a formação de professores dessa área que, por sua vez, precisa acontecer curricularmente, conforme Oliveira (2013, p. 93), “feita de dados e fatos emergentes do mundo ideado e prático da cotidianidade humana".

De forma didática e sucinta, Ghiraldelli (1988 apud MOREIRA, 1991, p. 20) aponta cinco tendências da Educação Física no Brasil: Higienista (até 1930), Militarista (1930-1945), Pedagogicista (1945-1964), Competitivista ou Esportivista (1964-1985) e Popular (pós 1985). Todas assumiam características do processo histórico-político da época a qual se situavam, e atrelada a esse processo, também estava a identidade de visão de homem e de mundo a que queriam formar.

A tendência Higienista, marcada pela presença do médico como personagem central, objetivava a manutenção do corpo robusto e sadio, a partir do exercício, com foco na disseminação de hábitos saudáveis impostos e que deveriam ser incorporados pela sociedade da época. A formação profissional estava vinculada às forças armadas e médica, não havia a figura do professor de Educação Física e priorizava-se, prioritariamente, a formação de militares com vistas à sua atuação na aplicação dos métodos ginásticos (DARIDO, RANGEL, 2008).

No período Militarista, a centralização do pensamento vigente era condicionada a formar indivíduos fortes, disciplinados e saudáveis prontos a combater e defender seu país. Selecionar os indivíduos considerados "perfeitos" fisicamente e excluir aqueles julgados incapacitados era o objetivo desta tendência. Como a ênfase estava voltada para o culto ao corpo sadio e atlético, a Educação Física dessa época não se apoiava nas dimensões conceituais e atitudinais, mas apenas nos procedimentos, então para ser professor bastava ser ex-atleta de qualquer modalidade esportiva. Essa afirmação aparece expressamente no entendimento de Darido e Rangel (2008):

Ambas as concepções, higienista e militarista, da Educação Física consideravam-na como disciplina essencialmente prática, não necessitando, portanto, de uma fundamentação teórica que a desse suporte. Por isso, não havia distinção evidente entre a Educação Física e a instrução militar. Para ensinar 
Educação Física não era preciso dominar conhecimentos, e sim ter sido um expraticante (p. 3).

Apesar da docência estar restrita a experiência, data dessa época, os avanços conquistados de uma formação do professor de Educação Física em dois anos, com a criação da Escola Nacional de Educação Física e Desporto (ENEFD), pela Universidade do Brasil, em 1939 (AZEVEDO; MALINA, 2004 apud BENITES et al., 2008, p. 346).

Dentro desse processo de evolução, surge a tendência Pedagogicista. Esta buscava chamar a atenção para uma Educação Física não apenas focada às questões corporais com o fim de prática saudável, mas como disciplina que assumia também propósitos educativos, que não visasse só a formação do físico, mas do indivíduo em todos os aspectos de sua constituição enquanto ser. Nesse caminho de contestar o que é vigente, do não conformismo com o trato que lhe era designado é que este campo foi sofrendo as primeiras reformulações curriculares com o intuito de advogar maior valor à profissão e aos profissionais docentes.

O curso de Educação Física nessa época passou para três anos de formação e começouse a exigir a conclusão do antigo $2^{\circ}$ ciclo (hoje Ensino Médio) para o ingresso na área. Isso aconteceu por volta de 1953 e somente em 1957 é que o curso perdeu o caráter de curso técnico. Data desse período também, a conquista da primeira Lei de Diretrizes e Bases da Educação LDB, 1961, que deu novos ares para a formação profissional.

Atinente à tendência Competitivista ou Esportivista, Darido e Rangel (2008, p.4) destacam que o "o papel do professor é bastante centralizador e a prática, uma repetição mecânica dos movimentos esportivos”. Verifica-se que a ideia central desta concepção era a seleção dos mais habilidosos, dos que mais conseguiam se destacar nos esportes. O modelo curricular era estritamente técnico e mecânico.

Concernente às conquistas no campo de formação docente, nesse período houve a implementação de uma nova grade curricular com 1800 horas, bem como o surgimento dos primeiros cursos de pós-graduação e proliferação dos cursos de graduação (BRASIL, 1969; FAUSTO, 2001 apud BENITES et al., 2008).

A epistemologia desta área passou a ser ressignificada com a chamada "crise de identidade" nos seus pressupostos e discursos sofridos na década de 80. A Educação Física passou a vislumbrar um ensino (para alunos) e a formação (de professores) num enfoque mais pedagógico e científico em que houvesse uma articulação das múltiplas dimensões do ser humano no processo de ensino e aprendizagem (BRASIL, 1997, p. 24). No ano de 1987, o curso de Educação Física passou a se delimitar em duas áreas acadêmicas distintas: bacharelado e licenciatura. A carga horária passou dos 1800 para 2880 horas-aula e o curso de três para quatro 
anos de duração, ocorrendo além disso, uma reformulação da sua episteme. (BRASIL, 1987, apud BENITES et al., 2008, p. 348).

A mudança no currículo e na formação do professore de Educação Física só foi possível ser percebida com o surgimento dos movimentos que assumiam novas abordagens pedagógicas, que buscavam tentar romper com os modelos biológicos e mecânicos, são algumas destas concepções: Psicomotricidade, Desenvolvimentista, Construtivista-interacionista, CríticoSuperadora, Crítico-emancipatória, dentro outras.

Nos dias atuais se busca um ensino e formação centrados na questão do movimento consciente e pensado, que valorize o potencial dos alunos e que tenha aportes teóricos que sustentem uma prática reflexiva e compromissada, que o movimento corporal tenha significado histórico e simbolismo cultural.

O avanço da sociedade traz aos professores "pressões" quanto ao seu posicionamento como educador. A atualidade requer do professor de Educação Física maior dinâmica e muito mais domínio dos assuntos específicos da sua área e também dos que não são específicos à sua formação. Essa exigência só é possível porque a prática tem sido ressignificada ao longo dos anos pela tentativa de romper com os modelos tradicionais de ensino. Segundo Lima (2007, p. 18), “educar crianças hoje exige de os professores saberes muitos distintos do que exigia dos professores que os ensinaram há 20 ou 30 anos". Juntamente com esses saberes distintos, Oliveira (2008, p. 5) destaca que para educar "é preciso acreditar na capacidade do outro de aprender".

Na formação em Licenciatura em Educação Física os professores passam a compreender curso como uma área de estudo do meio educacional e de campo profissional. Acentuado pela análise, ensino e aplicação das formas de conhecimentos sobre o movimento humano intencional e consciente nos seus aspectos comportamental, sociocultural e corporal (BRASIL, 2012).

A construção e produção do conhecimento emergem como pontos de significação comportamental. Barbosa-Rinaldi (2008) esclarece que a sustentação teórico-prática só é garantida pela formação profissional através do acesso à produção do conhecimento. Aponta que deve ser de forma responsável e levada em pauta os interesses do bem comum. Nestes aspectos, Nóvoa (1992) ratifica que os professores de Educação Física precisam estar preparados para gerar em seus alunos a crítica e a reflexão. E esse posicionamento crítico não pode ser aplicado apenas na teoria, ou no início da sua prática pedagógica como professor titular de uma turma, ela precisa ser apropriada desde o primeiro contato direto com os alunos, a partir da regência do estágio na graduação. 


\section{A formação colocada à prova: $1^{\circ}$ momento - estágio}

O estágio na graduação é um campo de conhecimento, segundo Pimenta e Lima (2006). E quando vislumbrado nessa perspectiva, a ele é atribuído status epistemológico com fins a superar a redução de mera atividade prática instrumental. Isto porque, comumente nos deparamos com a ideia de estágio sendo dissociado da teoria. Essa dicotomia acaba por não dar significado aos saberes do dia a dia aprendidos e prontos a serem vivenciados neste momento da graduação.

Nos anos iniciais do curso de formação do professor, a grande maioria, não tem experiência nenhuma com o ensino, a não ser o tempo que foi aluno. Não há experiência de sala de aula, de regência, de convívio com a comunidade escolar, e o estágio é o momento oportuno para essas aproximações. É nesta parte da formação que teoria e prática se misturam e, ambas levam "o principiante" a novas descobertas. Partindo da ideia de desvelar o que ainda não é conhecido, o que é novo, é que o desenvolvimento do estágio deve ser pautado por uma atitude investigativa, com vistas a promover a reflexão e a intervenção nos atores envolvidos no processo escolar e da sociedade (PIMENTA; LIMA, 2006).

É no estágio que os conteúdos estudados na universidade são testados e o professor em formação percebe técnicas não ensinadas nos bancos das faculdades, incorporando-as a sua identidade. Conforme Fontana e Guedes-Pinto (2007), é o estágio que permite ao futuro professor uma vivência muito mais real da educação e, também, traz a possibilidade de mensurar suas condições de novo educador no processo de ensino e aprendizagem. Isso só é possível devido ao contato que o estágio viabiliza ao futuro professor com a escola, local de sua atuação. É na escola que a prática é experimentada, vivenciada, avaliada e reexperimentada.

A carga horária dos cursos de licenciatura no Brasil está atualmente regulamentada pelo parecer CNE/CP N: 2/2015 que ampliou a carga horária de 2880 para 3200 horas-aula. Nessas 3200 estão incluídas as horas destinadas ao estágio supervisionado com duração mínima de um semestre letivo. De acordo com Silva Júnior et al. (2016, p. 1), o estágio "é um componente indispensável no processo de formação inicial, que oportuniza ao futuro professor a possibilidade de exercer a atividade profissional em seu campo real de intervenção”. É neste primeiro momento que é colocado à prova a aplicabilidade de seus conhecimentos no elo entre teoria e prática.

Por ser uma etapa importante da vida acadêmica, mais importante ainda é o compromisso dos futuros docentes com atuação ética. Não raro existem futuros professores que procuram formas de se eximir dessa responsabilidade. Alguns atribuem significados a esse 
momento como irrelevantes, consideram como perda de tempo, ou ainda, como um momento de valor apenas burocrático para a aquisição do canudo de graduação.

O estágio é o momento de aprendizado efetivo, é uma ponte com vistas a dar o real significado e pontapé inicial para a construção de uma prática pedagógica reflexiva e coadunada aos caminhos da construção de sua identidade profissional docente compromissada. Nesse ínterim, cabe ao futuro professor de Educação Física entender, desde sua formação, perpassada pelo estágio, o seu papel e função dentro da escola, o de promover em toda a comunidade escolar enriquecimento crítico e reflexivo de todas as suas ações enquanto docente em formação.

\section{A formação colocada à prova: $2^{\circ}$ momento - prática pedagógica enquanto professor titular}

Após as aulas na universidade, o primeiro contato do estágio, a reflexão sobre a continuidade na carreira pedagógica e a conclusão do curso, se subtende que o professor, agora formado, se depara com a responsabilidade e o papel de ser o professor titular da disciplina. E neste contexto o professor formado em Educação Física se encontra diante da autonomia e criatividade para ministrar aulas que proporcione o desenvolvimento, não apenas físico, mas também cognitivo, cultural e social dos alunos através da sua prática pedagógica.

Para tanto, podemos definir prática pedagógica em Educação Física de acordo com Betti (2005, p. 188) "como aquela dinâmica comunicativa, repleta de intencionalidades e valores, na qual interagem o professor/profissional, o aluno/cliente/atleta, e as possibilidades da cultura corporal de movimento, por intermédio de várias linguagens (corporal, verbal, etc.)".

No que diz respeito às referências para a prática pedagógica, na tentativa de uma uniformidade nacional, o Ministério da Educação-MEC (BRASIL, 1998), dispõe os Parâmetros Curriculares Nacionais (PCNs), bem como também a Base Nacional Comum Curricular (BNCC). No que é referente a Educação Física a recomendação encontrada nesses textos é construir os questionamentos essenciais que o professor deve considerar no desempenho do seu trabalho, dando base as reflexões, os planejamentos e as conjecturas da prática de Educação Física.

E ainda levar em consideração a democratização e humanização nas aulas, na busca sempre de forma diferenciada da prática pedagógica da área, para que se possa ampliar as concepções pedagógicas, saindo de um pensamento biológico para um pensamento que incorpore as dimensões afetivas, cognitivas e socioculturais dos discentes. 
Diante dessas perspectivas, percebe-se que a prática pedagógica em Educação Física, permeia muito mais do que o âmbito racional e técnico, abrangendo sua funcionalidade e participação no desenvolvimento do ser de forma mais ampla. É o mesmo que afirmar que ao mesmo tempo onde se analisa e desenvolve aspectos motores também se aprimora e refina funções intelectuais, além do social, na interação do grupo e cultural, na apresentação das diferentes formas de movimento corporal.

O professor precisa, assim como em qualquer outra profissão, estar ciente e preparado para lidar com os desafios encontrados no percurso, desafios esses, que no caso da Educação Física, pode se apresentar como resistências e visões contrárias a inserção da mesma dentro da escola além do desinteresse dos alunos, ou ainda falta de apoio da comunidade escolar.

Isso leva a crer que todo professor de Educação Física precisa estar apto a lidar com a indiferença e em sua prática demonstrar a importância dessa ciência e seu saber. Neste sentido, Haag et al. (2016, p. 152) relata que "é irônico e de fato preocupante que mesmo em lugares em que por lei a Educação Física tem o mesmo estatuto que as outras disciplinas do currículo escolar, professores de educação física tenham de lutar para garantir seu efetivo cumprimento".

Assim, a atuação como professor, seja ela no estágio ou no cotidiano quando já efetivado, em participação com a escola deve demonstrar a importância dessa disciplina e seu saber, possibilitando aos alunos melhores conhecimento de si mesmo e do ambiente ao seu redor, despertando através do movimento corporal e sua cultura novos saberes e autonomia.

\section{Considerações finais}

O estudo mostra que o fator histórico é significativamente relevante para a transformação do processo de formação dos professores de educação física. Todas as alterações sociais e epistemológicas impactaram de forma direta a tríade formação - estágio - prática pedagógica, moldando essa área do conhecimento, a estrutura curricular, os profissionais e sua prática pedagógica. A discussão do tema mostra que durante o processo histórico de formação, a concepção do professor de educação física esteve arraigada ao modelo técnico, onde a ênfase do ensino estava na aptidão física e no rendimento padronizado.

No entanto, com os giros epistemológicos foi-se superando esse viés estritamente técnico e desvelando outras nuances da formação. Embora, Barbosa-Rinaldi (2008) saliente que ainda hoje, a racionalidade técnica ou tecnológica (instrumental) se faz hegemônica nos cursos de Educação Física, no currículo ou no fazer pedagógico dos docentes. 
É justamente por essa permanência, em muitos casos, de uma atuação ainda voltada a prática tecnicista e preocupada apenas no êxito de movimentos corpóreos desprovidos de significados e relevância para a aprendizagem do aluno, que a valorização e importância ao estágio, deve ser reflexiva tangente quanto da formação da identidade do professor. No que concerne à prática pedagógica, uma concepção reflexiva e crítica dos conteúdos que leciona feita pelo professor de Educação Física, valoriza sua permanência na escola.

A reflexão sobre a formação inicial dos professores de educação física mostra que o educador deve aprimorar cada vez mais no que diz respeito ao conhecimento associado a realidade da comunidade escolar a que está inserido. Isso será capaz de gerar nos alunos mais apreço e interesse pelos conteúdos relacionados à sua prática. É também importante que os saberes relacionados à cultura de movimento corporal sejam valorizados e que o professor perceba e desenvolva formas dinâmicas de como viabilizar as descobertas e os estudos em relação ao movimento corporal.

\section{REFERÊNCIAS}

BARBOSA-RINALDI, Ieda Parra. Formação inicial em Educação Física: uma nova epistemologia da prática docente. Movimento, Porto Alegre, v. 14, n. 03, p. 185-207, setembro/dezembro de 2008. Disponível em:

http://www.seer.ufrgs.br/index.php/Movimento/article/view/2431. Acesso em: 23 jan. 2018.

BENITES, Larissa Cerignoni; SOUZA NETO, Samuel; HUNGER, Dagmar. O processo de constituição histórica das diretrizes curriculares na formação de professores de Educação Física. Educação e Pesquisa, São Paulo, v. 34, n. 2, p. 343-360, maio/ago. 2008. Disponível em: http://www.scielo.br/scielo.php?script=sci_arttext\&pid=S1517-97022008000200009. Acesso em: 19 jan. 2018.

BETTI, Mauro. Educação física como prática científica e prática pedagógica: reflexões à luz da filosofia da ciência. Revista Brasileira de Educação Física e Esporte. São Paulo, v. 19, n. 3, p. 183-97, jul./set. 2005. Disponível em:

http://www.revistas.usp.br/rbefe/article/view/16594. Acesso em: 19 jan. 2018.

BRASIL. Secretaria de Educação Fundamental. Parâmetros curriculares nacionais: Educação física. Secretaria de Educação Fundamental. Brasília, MEC/SEF, 1988.

BRASIL. Lei de Diretrizes e Bases da Educação Nacional. Lei número 9394, 20 de dezembro de 1996.

BRASIL. Instituto Federal de Educação, Ciências e Tecnologia de Roraima. Plano de Curso de Licenciatura em Educação Física. Boa Vista-RR, 2012. Disponível em: www.ifrr.edu.br. Acesso em: 21 jan. 2018. 
BRASIL. Ministério da Educação - Conselho Nacional de Educação. Do parecer no tocante as Diretrizes Curriculares Nacionais para a Formação Inicial e Continuada dos Profissionais do Magistério da Educação Básica. Parecer normativo, n. 2, de 9 de junho de 2015.

Disponível em: http://porteiras.r.unipampa.edu.br/portais/prograd/files/2015/06/Par.-02.2015DCNs-Forma\%C3\%A7\%C3\%A3o-Professores.pdf. Acesso em: 27 fev. 2018

BRASIL. Ministério da Educação. Secretaria da Educação Básica. Base nacional comum curricular. Brasília-DF, 2016. Disponível em:

http://basenacionalcomum.mec.gov.br/\#/site/inicio. Acesso em: 20 jan.2017.

CASTELLANI FILHO, Lino. Educação Física no Brasil: A história que não se conta. $19^{\circ}$ edição. Campinas-SP. Papirus, 2013.

DARIDO, Suraya Cristina.; RANGEL, Irene Conceição Andrade. Educação Física na Escola: Implicações Para a Prática Pedagógica. 2008. Ganabara Koognan.

FONTANA, Roseli Aparecida Cação; GUEDES-PINTO, Ana Lúcia. Desatando os nós da formação docente - trabalho escolar e produção do conhecimento. Editora Mediação. Porto Alegre, 2002. p. 5-22.

FREIRE, Paulo. Educação como prática da liberdade. Rio de Janeiro: Paz e Terra, 1974.

GATTI, Bernardete Angelina. Formação de professores no Brasil: características e problemas. Educação Sociedade. Campinas, v. 31. n. 113. p. 1355-1379, out./dez., 2010. Disponível em: http://www.scielo.br/pdf/es/v31n113/16.pdf. Acesso em: 10 fev. 2018.

HAAG, Herbert.; KESKINEN, Kari.; TALBOT, Margaret. Diretório da ciência desportiva - Juiz de Fora: NGIME/UFJF, 2016. 6. ed. Disponível em:

http://cev.org.br/arquivo/biblioteca/4037171.pdf. Acesso em: 12 fev. 2018.

LIMA, Elvira Souza. Indagações sobre Currículo: Currículo e desenvolvimento humano Brasília: Ministério da Educação, Secretária de Educação Básica, 2007.

MOREIRA, Wagner Wey. Educação Física Escolar - Uma abordagem fenomenológica. Editora da Unicamp. Campinas-SP, 1991.

NÓVOA, António. A Formação de professores e profissão docente. In: NÓVOA, A. Os professores e a sua formação. Lisboa: Publicações Don Quixote, 1992. p. 13-33.

OLIVEIRA, Elialdo Rodrigues. Reflexão educativa na reconstrução da dignidade da pessoa humana. In: Reflexões Educacionais a Partir de Novos Talentos. Boa Vista: Editora da UERR, 2012, p. 119-142.

OLIVEIRA, Elialdo Rodrigues de. Introdução. In: UNIVERSIDADE ESTADUAL DE RORAIMA. Projeto Pedagógico do Curso de Filosofia. Boa Vista, RR: Universidade Estadual de Roraima, 2008, p. 4-5.

OLIVEIRA, Elialdo Rodrigues de.; CLEMENTE, Ana Maria.; SOUZA, Ana Hilda Carvalho de. Currículo e Multiculturalismo na Formação de Professores: Pontos Convergentes. In: II 
Anais do Projeto Novos Talentos CAPES-UERR. Da Ciência à Cidadania. Boa Vista/RR: Editora da UERR, 2013, p. 93-100

PIMENTA, Selma Garrido e LIMA, Maria Socorro Lucena. Estágio e docência: diferentes concepções. Revista Poíesis -Volume 3, Números 3 e 4, pp.5-24, 2005/2006. Disponível em: https://www.revistas.ufg.br/poiesis/article/download/10542/7012. Acesso em: 19 fev. 2018.

SAVIANI, Dermeval. Formação de professores no Brasil: dilemas e perspectivas. Poíesis Pedagógica, v. 9, n.1, p. 7-19, jan./jun., 2011. Disponível em: file:///C:/Users/ufrr/Downloads/15667-63261-1-PB.pdf. Acesso em: 13 fev. 2018.

SAVIANI, Dermeval. Formação de professores: aspectos históricos e teóricos do problema no contexto brasileiro. Revista Brasileira de Educação v. 14 n. 40 jan./abr. 2009. pp. 149-155. Disponível em: file:///C:/Users/ufrr/Downloads/v14n40a12.pdf. Acesso em: 17 fev. 2018

SILVA JÚNIOR, et al. Estágio curricular supervisionado na formação de professores em educação física: uma análise da legislação a partir da resolução cfe nº 03/19871. Pensar a Prática, Goiânia, v. 19, n. 1, jan./mar. 2016. Disponível em https://www.revistas.ufg.br/fef/article/viewFile/34854/pdf. Acesso em: 19 de fev. 2018.

TANURI, Leonor Maria. História da formação de professores. Revista Brasileira de Educação, n. 14, p. 61-193, maio/ago., 2000. Disponível em: http://www.scielo.br/pdf/rbedu/n14/n14a05. Acesso em: 13 fev. 2018.

\section{Como referenciar este artigo}

VASCONCELOS, Jardielly Alencar.; SERAFIM, Neemias Elnatan.; OLIVEIRA, Elialdo Rodrigues de. A formação inicial de professores de Educação Física alinhada às perspectivas históricas: do estágio à prática pedagógica. Revista on line de Política e Gestão Educacional, Araraquara, v. 22, n. 3, p. 1140-1153, set./dez., 2018. E-ISSN:1519-9029. DOI: 10.22633/rpge.v22i3.11360

Submetido em: $11 / 05 / 2018$

Aprovado em: 25/08/2018 